\title{
Technical and economic assessment of energy from Tidal Currents
}

\author{
Isabel Páscoa ${ }^{1}$, C. Camus ${ }^{1}$ and E. Eusébio ${ }^{1}$ \\ ${ }^{1}$ Department of Power Systems Engineering and Automation, I.S.E.L, Instituto Politécnico de Lisboa \\ Rua Conselheiro Emídio Navarro nº1, 1959-007 Lisboa (Portugal) \\ Phone: +351 218317000, e-mail: $33360 @$ alunos.isel.pt, ccamus@ deea.isel.ipl.pt, \\ eaeusebio@deea.isel.ipl.pt
}

\begin{abstract}
The present work aims to study the feasibility of deploying a farm of sea current turbines for electricity generation in Portugal. An approach to the tides, which are they, how they are formed, its prediction, is held. It is also conducted a study about the energy of sea currents and it is presented some technology about ocean currents too. A model of tidal height and velocity of the currents it is also developed. The energy produced by a hypothetical park, built in Sines (Portugal), is calculated and afterwards, an economical assessment is performed for two possible scenarios and a sensitivity analysis of NVP (Net Present Value) and LCOE (Levelized Cost of Energy) is figured. The conclusions about the feasibility of the projects are also presented. Despite being desired due to its predictability, this energy source is not yet economically viable as it is in an initial state of development. To push investment in this technology a feed-in tariff of, at least $€ 200 / \mathrm{MWh}$, should be considered.
\end{abstract}

\section{Key words}

Energy, Renewable, Tidal Energy, Economic Assessment.

\section{Introduction}

Regarding to renewable energy sources in Portugal, there is an enormous potential to explore, not only to reduce carbon emissions but also to diminish the import of fossil fuels. In 2013 in Portugal, 58\% of the electricity produced came from renewable sources, only $37 \%$ came from fossil fuels and 5\% was imported. The renewable energies with bigger impact were hydro power - $26 \%$ of production from a renewable source and wind power with $23 \%$, despite the increasing evolution of solar energy [1].

With the growing demand for renewable energy, resources coming from the sea become an emerging form of energy source. The oceans are the largest of all natural resources, thus its potential energy can contribute to the growing needs of energy. In the oceans as the main sources of energy we have waves, sea currents and ocean thermal energy. The energy is stored in the oceans, in part as heat energy, partly as kinetic energy (waves and currents) and also in chemical and biological products.
Only a fraction of the global ocean energy resource can be found in economically viable places to explore with the available technology. However, this can significantly contribute to the European Energy supply, and the marine renewable energy sector is currently the focus of much industrial and academic research worldwide. Among the extracted energy resources of the oceans, waves and ocean currents are emerging as the most promising option of mass power generation. Portugal has a great potential for harvesting energy from ocean currents, it has a large coastal area. Nevertheless, in Portugal a single central to capture energy from waves on the island of Pico in the Azores.

The electrical power from ocean currents is a fairly predictable source. This source offers a vast and reliable source of energy [2].

\section{Tidal Energy}

For the conversion of energy from sea currents, turbines which convert the kinetic energy of the fluid in which they are immersed, into mechanical energy, are used. These turbines are then coupled to a generator to produce electrical energy. This type of exploitation corresponds essentially to exploit the kinetic energy associated with the flow of water moved by sea currents. The technique follows the same basic principles of operation of wind turbines with the difference that they use water to be moved and that the density of water passing through the turbine is about 800 times higher than air. Some aspects must be taken into account: it requires a minimum current velocity; restricted to areas with strong currents, usually in shallow depths; robust structure that requires little maintenance. These turbines reach their maximum efficiency when they are situated in an area with swift currents with natural flows between rocky points, headlands, between islands, entry bays, rivers or other rock masses. When they feel the funnel effect (recesses with gradual narrowing) or resonance (when there is an indentation on the coast that reflects the current in the background and its mouth). 

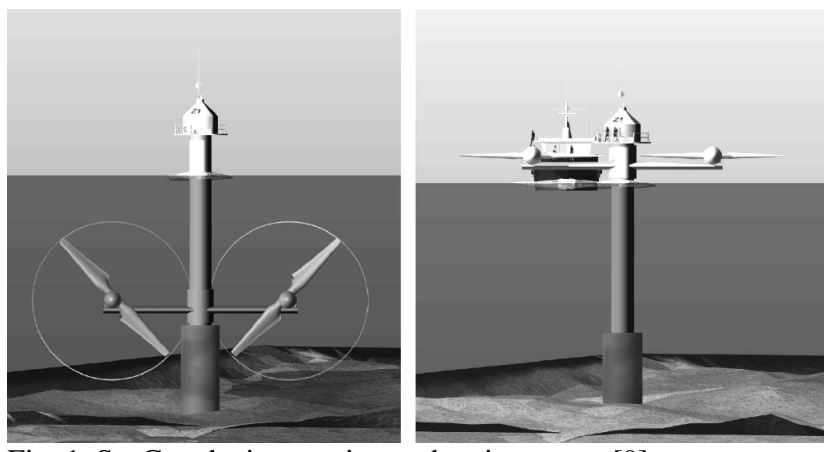

Fig. 1. SeaGen device moving and maintenance [9]

\section{A. What are tides}

Tides are developed by the movement of sea water due to changes in the attraction between the Moon and the Sun on the Earth's rotation forces. There are also ocean currents caused by the Coriolis force due to the rotation of the Earth acting on the waters of the oceans forces. Currents can also be generated by density differences resulting from variations in the level of salinity and temperature in different sea areas. The rise and fall of the tides accompanied by a horizontal movement of water called the sea [3] currents. The Moon is the main influencer of the formation of tides because the moon is 389.1 times closer than the sun. Mathematically the tide is a sum of sinusoids (constituent waves) whose frequency is known and depends solely on astronomical factors.

\section{B. Technologies}

Like other renewable energies, also for the energy of sea currents, it is possible to find a wide variety of power converters. The various types are available:

- Horizontal axis turbine;

- Vertical axis turbine;

- Oscillating Hydrofoil;

- Venturi effect devices;

- Helical Screw;

- Tidal Kite;

- Tidal dams.

In addition to the various types of power converters there are also several fixation options, as shown in Fig.2.

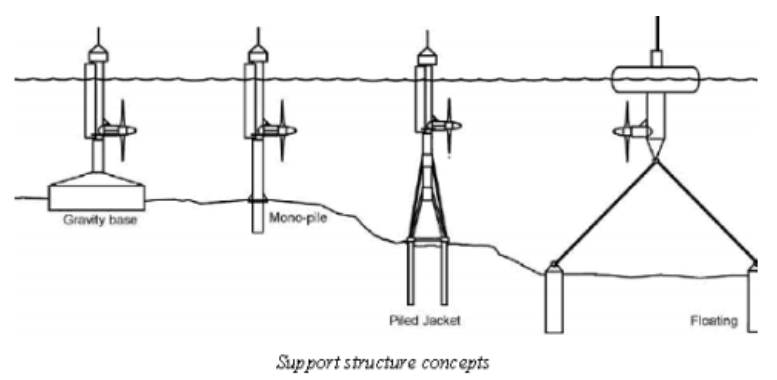

Fig. 2. Types of fixation for power converters [4]
Turbines are mounted on a support structure that is a key of tidal currents devices being a requirement to keep them operating on a severe marine environment. The choice depends mainly on the basis of geographical conditions such as water depth, sea bottom conditions, rivers and the type of turbine to be installed. Moreover, it is an important aspect of the viability and profitability of the devices [4].

\section{Characteristics of installation}

Generic features that should be taken to account when installing a parking turbine marine currents are mentioned below:

- Maximum diameter: a reasonable diameter to consider depends on the state of the art. It is believed that the diameter is limited to $20-25 \mathrm{~m}$ to a horizontal axis turbine;

- Upper Clearance: Must be considered a superior clearance for the capture area of the rotor. The minimum distance of $5 \mathrm{~m}$ from the top is usually recommended to allow recreational activities (small boats, swimming, etc.), and to minimize the effects of turbulence and wave on the turbine as well as damage from floating materials;

- Bottom Clearance: It is recommended that a bottom clearance of $25 \%$ of water depth or $5 \mathrm{~m}$, whichever is greater, should be considered a minimum to allow materials that are potentially moved along the seabed by currents not impair the turbine and to minimize the turbulence and the deformation of the bottom boundary layer;

- Spacing: The lateral spacing between the devices (the wheelbase) should be two half rotor diameter $(2,5 \mathrm{xd})$, the spacing should be downstream (10xd) and times. The devices must be positioned in an alternating arrangement downstream [5].

\section{Methodology conversion}

The sea current systems employ the kinetic energy of the moving water to power turbines the same way as wind turbines use air movement. Thus the power available from the water flow is given by equation (1):

$P=\frac{1}{2} \rho A V^{3}$

Where $\rho$ is the water density, A is the cross sectional area of the rotor, and $\mathrm{V}$ is the velocity of the stream. This cubic relationship between speed and power is justified as the same power curves of wind turbines, and as wind power, there are practical limits to the amount of energy that can be extracted from tidal currents, so the energy generation is very sensitive to the stream speed. Some of these limits relate to the design of tidal currents devices. The kinetic energy of the stream that can be converted into mechanical energy in a usable form is limited by the performance of the device, as shown in the following equation (2): 
$P_{T}=\frac{1}{2} \rho C_{P} A V^{3}$

Where $\boldsymbol{C}_{\boldsymbol{P}}$ is the power coefficient, its value for a turbine flow of incompressible fluid is limited to a theoretical maximum of Betz Limit. The Betz limit is a theoretical upper limit on the power output of a turbine whose blades sweep an area. Which is expressed as a maximum power coefficient rotor $\boldsymbol{C}_{\boldsymbol{P}}=16 / 27$, which is $59 \%$ [8].

\section{D.1. Methodology}

To calculate the height of the tide is necessary to develop a harmonic analysis. It is named of harmonic analysis the mathematical process by which the tide observed at a given site is separated into simple harmonic components. Its purpose is to determine the amplitude $H$ (in m) and $g$ the phase (degrees) of the different harmonic components of the tide, from the recorded number of tide measurements. The phase of a harmonic tidal constituent is delayed with respect to the tide called equilibrium. In practice, the tide height $h(t)$ will be calculated as the parameters of the following harmonic formula that best fit time series:

$h(t)=A_{0}+\sum_{t}^{n} f_{i} H_{i} \cos \left[w_{i} t+\left(v_{o}+u\right)_{i}-g_{i}\right]$

where $h(t)$ is the height of water at time $t$, is the period of $g_{i}$ constituent $f_{i}$ is the factor node (that reduces the average amplitude $H_{i}$ per year of forecast), $H_{i}$ is the average amplitude, the values wi represent the angular velocities of the constituent waves, $v_{0}+u$ is your initial argument, the argument is that the tide of balance for the initial time series data and $\mathrm{A}_{0}$ is the average level of the port. The importance of applying the harmonic formula due to its universality that is suitable for any type of tidal [6].

For the calculation of stream velocity it is known that the tidal cycle can be approximated by a double sinusoid; with a period of $12.4 \mathrm{~h}$ representing the diurnal tide ebb and flow of the cycle and the other with a period of 353 hours representing the period of bi spring tides. The following equation provides a reasonable model for predicting the speed V of a tidal stream:

$V=\left[K_{0}+K_{1} \cos \left(\frac{2 \pi t}{T_{1}}\right)\right] \cos \left(\frac{2 \pi t}{T_{0}}\right)$

Where $\boldsymbol{K}_{\mathbf{0}}$ and $\boldsymbol{K}_{\mathbf{1}}$ are constants derived from the peak to average ratio between the spring and the spring average peak and the average peak current dead. $\boldsymbol{T}_{\mathbf{1}}$ is usually 353 hours and Tide is the length of the spring. $\boldsymbol{T}_{\mathbf{0}}$ is the period of semi-diurnal tides and is 12.4 hours. Other factors, which could cause a significant influence on the speed of the tidal stream, like ripples on the surface, the residual force, navy global ocean circulation, changes in density and variation in water velocity as a function of the depth of flow in a open channel, have to be considered and need to be reflected in the prediction equations for the speed of tidal currents.

As in the case of wind turbines, marine turbine efficiency varies with the speed of the water flow. A batch outlet of the turbine as a function of the flow velocity consists of three regions:
I. Zero to cut-in speed
II. Cut-in speed to rated speed
III. Greater than rated speed

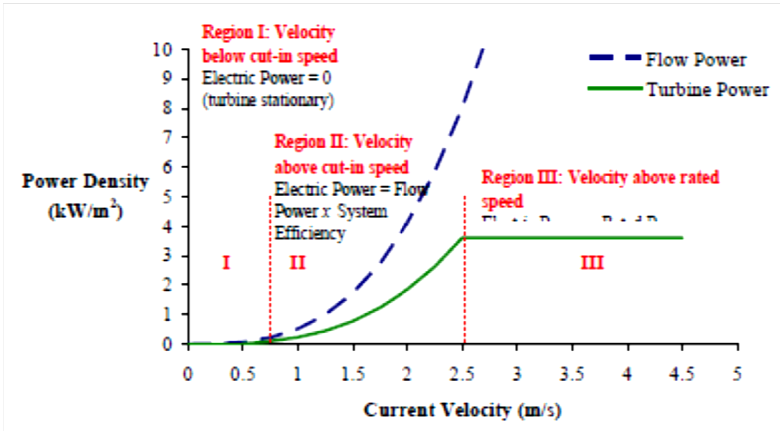

Fig. 3. Typical output power versus flow of the turbine speed [7]

In region I, at speeds below the speed of driving, the turbine cannot rotate and therefore does not generate energy. In region III, when the current speed exceeds the rated speed of the turbine, the power will be constant, usually the rated power of the turbine, regardless of the stream speed. The rated output power is maintained by either applying a braking force to the rotor axis or by changing the pitch angle of the turbine blades, to produce less torque. There is no cut-out rate for a tidal flow turbine, since even the most extreme storm currents produced by creating the highest tides are not much larger than the current maximum monthly spring. Unlike wind turbines, which must be designed to cope with the peak wind speed, which is several times higher than the typical speed of wind maximum monthly [7].

\section{D.3. Economic Evaluation}

The NPV (Net Present Value) aims to assess the feasibility of an investment by calculating the present value of all its cash flows. The cash flow in each year represents the net revenue expected to get in the future. Like any investment, you only get return in the future, so it is necessary to update the value of each cash flow and compare them with the value of the investment. In case the value of the investment is less than the present value of cash flows, the NPV is positive which means that the project has a positive yield.

$N P V=\sum_{t=1}^{n} \frac{C F_{t}}{(1+i)^{t}}$

NPV - Net Present Value

$n$ - Lifetime;

$\mathrm{t}$ - Year of the cash flow;

$C F_{t}$ - Cash flow for the year $\mathrm{t}$;

$\mathrm{i}$ - Discount rate.

The LCOE (levelized Cost Of Energy) is the sum of capital and operating and maintenance costs during the 
life spam divided by generation of electricity during the lifetime. The LCOE is an economic assessment of the cost of the power generation system, including all the costs over its lifetime: initial investment, operations and maintenance, cost of fuel, cost of capital. However, it is a complex indicator to determine as it depends on many factors. Some of them rely heavily on the central location, the capacity and costs of O\&M factor, while the discount rate is dependent on the investor's decision. The following equation shows how the LCOE was calculated.

$L C O E=\frac{\text { Total updated costs }}{\text { total updated energy }}=\frac{I+\operatorname{Com} * k_{a}}{E_{a} * k_{a}}$

$K_{a}=\frac{1}{i}-\frac{1}{i(1+i)^{n}}$

\section{I - Investment}

Com - Operation and maintenance costs

$k_{a}$ - is the annuity factor which reflects the sum of the series that defines the update

\section{Case study}

\section{A. Local}

It was considered the implementation of a marine energy park in Sines, with three turbines of $1.2 \mathrm{MW}$ each, with a total of 3.6 MW. From the one year hourly tidal data, an example of a 48 hours of tidal height in Sines is depicted in Fig. 4.

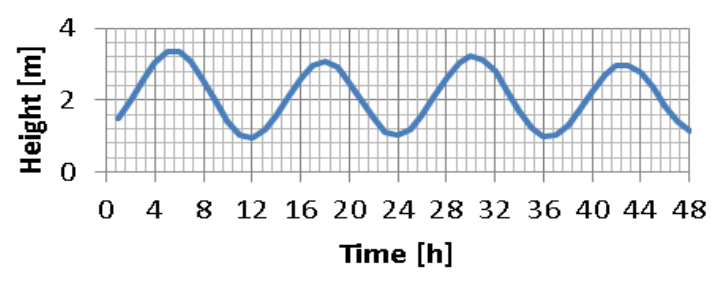

Fig. 4. Curve of the height of the tides in Sines $48 \mathrm{~h}$ period

\section{B. Approximate velocity curve}

Two sinusoidal curves were calculated, as there are spring tides which have high amplitudes and neap tides with smaller ones. To perform this calculation the following sinusoidal function was used

$C=A_{0} \cos \left(\frac{2 \pi}{p}(t-\alpha)\right)$

The value of $A_{0}$ is related to the average height of tides in Sines in 2013, ie for $C_{1}$ function (9) this value corresponds to the average for the neap tides and for the $C_{2}$ function (10) it is the average value for spring tides. For $C_{1}$ function, which corresponds to the neap tides, it was considered for the value of $A_{0}=0.8$ for the period $\mathrm{P}=12.45$ hours and $\alpha=4.8$ hours. For $C_{2}$ function, which corresponds to the spring tide, it was considered for the value of $A_{0}=2$, for the period $\mathrm{P}=708$ and $\alpha=-45$. It is known that the period of the wave is not always the same, since both the sun and the moon will influence the tides so that the periods change, and different times were used so as to equation (9) to (10).

$$
C_{1}=0,8 \cos \left(\frac{2 \pi}{12,45}(t-4,8)\right)
$$

$$
C_{2}=2 \cos \left(\frac{2 \pi}{708}(t+45)\right)
$$

To achieve at the approximate curve the mean value of the height, to which is added one of two options is calculated: if the $C_{2}$ is greater than 1 , multiplies the $C_{1}$ by $C_{2}$, otherwise if $C_{2}$ is smaller than -1 is multiply $\left(-C_{1}\right)$ by $C_{2}$ otherwise $C_{1}$, ie:

$$
h(t)=\bar{h}+\left\{\begin{array}{c}
C_{2}>1, \text { then } C_{2} \times C_{1} \\
C_{2}<-1, \text { then }-C_{1} \times C_{2} \\
-1 \leq C_{2} \leq 1, \text { then } C_{1}
\end{array}\right.
$$

where:

$\mathrm{h}(\mathrm{t})$ - approximate curve heights of tides.

$\bar{h}$ - Average real heights.

$C_{1}$ - Corresponding to neap tides curve.

$C_{2}$ - Curve corresponding to spring tides.

Thus, it was possible to approximate the real data by the function $\mathrm{h}(\mathrm{t})$ as shown in Fig. 5.

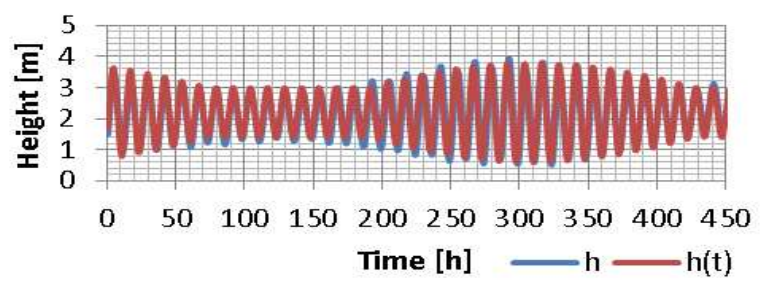

Fig. 5. Height versus time for Sines and the tidal waveform approximated

As there are no data speeds of marine currents in Portugal it was necessary to calculate them by extrapolating the data from other places where both tidal and currents data was available. Data from the USA of both annual tide heights and stream currents for the same site was found at the NOAA (National Oceanic and Atmospheric Administration [10]. For instance, the variation of the speed and height of sea currents in Tampa Florida, is represented in Fig. 6, as an example. The stream velocity is zero when the height is a maximum or a minimum and when it is not in the maximum points is the absolute value of the difference in heights multiplied by a multiplicative factor.

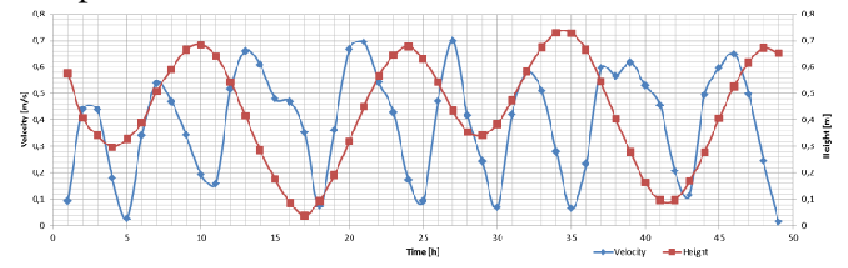

Fig. 6. Varying the speed and height of sea currents in Tampa Florida

To find the velocities of ocean currents to the tides of Sines we took into account the relationship between tidal 
heights and velocities of America, of which data from four different seasons, all with the same kind of tide of Portugal were analyzed. To determine the relationship between the heights and speeds it was defined a function that determines at each instant the current value from the height of the tide in order to find this relationship and considers it a multiplicative factor. To that, it was minimized the sum of the difference of the actual speed value minus the calculated squared value with a change of the multiplicative factor, as can be seen in Equation (12). This solution of the multiplicative factor was performed for the four different stations (Florida, Cape Henry, New London and Thimble Shoal), the solution chosen was the one that gave lower multiplicative value, because these values are approximate values and by choosing a larger value currents will be larger and the error will be greater.

$$
\begin{gathered}
\min \sum\left(V_{i}(t)-V_{h}(t)\right)^{2} \\
\text { s. } a \\
f m \geq 1 \\
f m \leq 7
\end{gathered}
$$

$$
V_{h}(t)=\left\{\begin{array}{c}
0, \text { if was maximum or minimum } \\
\left(h_{t}-h_{t+1}\right) \times f m
\end{array}\right.
$$

Where:

$V_{i}(t)$ - Speed value of the current in real time $t$

$V_{h}(t)$ - Function of the approximate speed of the current $\mathrm{fm}$ - Multiplicative factor

$h_{t}$ - Height of the tide in real time $\mathrm{t}$

$h_{t+1}-$ Height of the tide in real time $t+1$.

Thus the approximate curve of current velocities is given

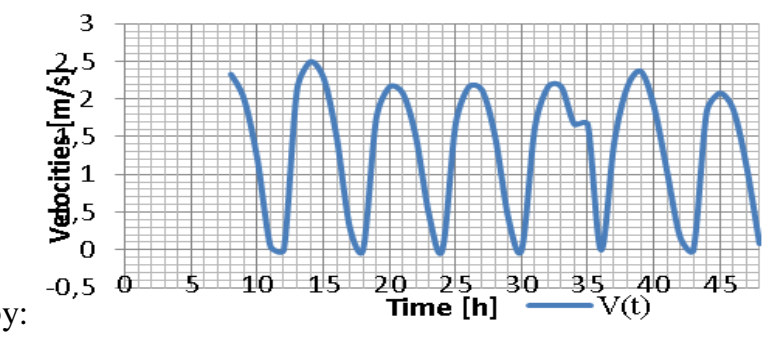

Fig. 7. Approximate curve for velocities of currents

\subsection{Expected annual energy production}

An estimation of the annual energy produced with 3 horizontal axis turbines was conducted with the hourly expected values of the stream currents in Sines and the turbines' output power given by its power curve in Fig.8.

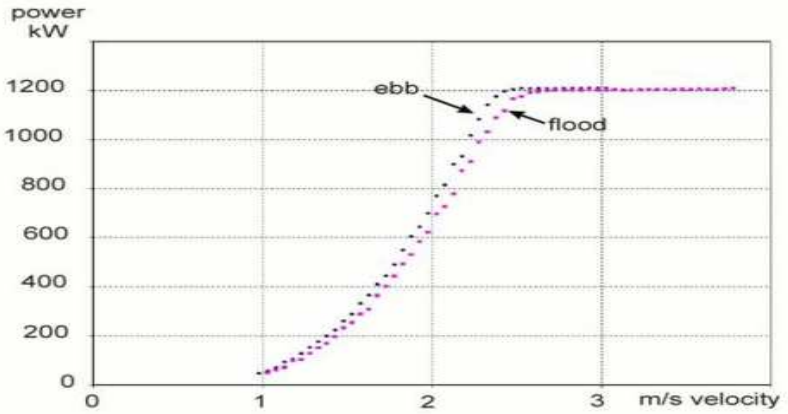

Fig. 8. Power curve SeaGen 1,2 MW

With the power curve was found a tendency line polynomial $3^{\text {rd }}$ order for the flood and ebb. Knowing that the flood and ebb they last each one about 6 hours, the power for each hour was calculate by Equation (13):

$$
\left\{\begin{array}{l}
\text { If } u<0,8, \text { then } P=0 \\
\text { If } 0,8<u<2,52 \text { and flood, then } \\
P=-266,29 u^{3}+1732,8 u^{2}-2718,7 u+1323,4 \\
\text { If } 0,8<u<2,32 \text { and } e b b, \text { then } \\
P=3,2645 u^{3}+447,96 u^{2}-659,58 u+259,76 \\
\text { If } u \geq 2,52 \text { and flood or } u \geq 2,32 \text { and } e b b, \\
\text { then } P=P_{n}
\end{array}\right.
$$

Thus, Anually Energy Produced is calculated by:

$$
E_{a}=\sum P_{h} \cdot \text { Number of Turbines }
$$

Where:

$\mathrm{E}_{\mathrm{a}}-$ Annual Energy Produced

$\mathrm{P}_{\mathrm{h}}$ - Power per hour.

\subsection{Profitability}

Cash flows were calculated annually, taking into account duration of the project, considered the life of the turbines 25 years.

Case1: Considering that this energy has no energy policy support, Thus revenues are calculated multiplying expected energy produced by market prices.

Case 2: Considered a feed-in tariff of 200€/MWh.

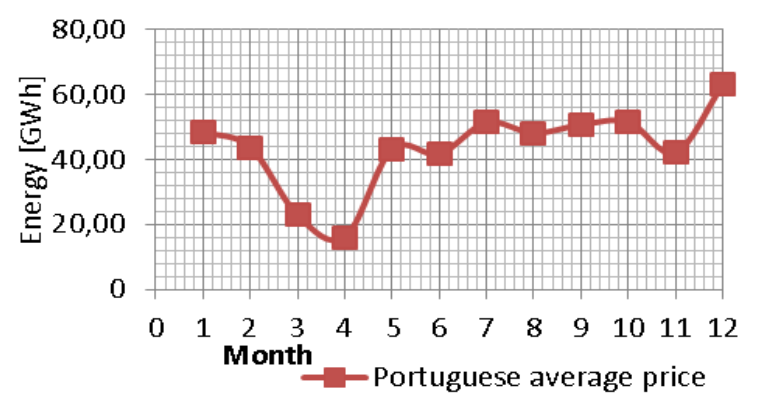

Fig. 9. Average market Price of Portugal in the year of 2013

With a $10 \%$ discount rate, table I summarizes the main economic indicators.

Table I. Results Summary

\begin{tabular}{|l|c|c|}
\hline Results & Case 1 & Case 2 \\
\hline NPV [M€] & -12.95 & 4.79 \\
\hline
\end{tabular}




\begin{tabular}{|l|c|r|}
\hline Payback [years] & - & 13 \\
\hline LCOE [€/MWh] & 197.8 & 197.8 \\
\hline IRR [\%] & - & 13.5 \\
\hline
\end{tabular}

\subsection{Project Sensibility}

There are a lot of uncertainties in this assessment so a sensitivity analysis is fundamental to find the critical variables and to construct different possible scenarios. The considered variables for sensitivity analysis were: Current speed, load factor, market price and feed-in tariffs, equipment live time, discount rate and total investment. Tables II and III summarize the results.

Table II. Summary sensitivities for case1

\begin{tabular}{|l|c|c|c|c|c|}
\hline \multirow{2}{*}{\multicolumn{1}{|c|}{ Analysis }} & \multicolumn{4}{|c|}{ NVP } \\
\cline { 2 - 3 } & \multicolumn{2}{|c|}{$-5 \%$} & Base & \multicolumn{2}{c|}{$+5 \%$} \\
\hline & {$[\mathrm{M} €]$} & $\%$ & {$[\mathrm{M} €]$} & {$[\mathrm{M} €]$} & $\%$ \\
\hline Current speed & -13.70 & 5.69 & & -12.23 & 5.69 \\
\hline Load factor & -13.09 & 1.08 & & -12.81 & 1.08 \\
\hline Market price & -13.09 & 1.08 & \multirow{3}{*}{-12.95} & -12.80 & 1.16 \\
\hline Life time & -13.20 & 1.9 & & -12.80 & 1.3 \\
\hline Discount rate & -12.60 & 2.6 & & -13.20 & 2.2 \\
\hline Investment & -12.1 & 6.6 & & -12.8 & 6.6 \\
\hline
\end{tabular}

Table IIII. Summary sensitivities for case2

\begin{tabular}{|l|c|c|c|c|c|}
\hline \multirow{2}{*}{\multicolumn{1}{|c|}{ Analysis }} & \multicolumn{5}{|c|}{ NVP } \\
\cline { 2 - 3 } & \multicolumn{2}{|c|}{$-5 \%$} & Base & \multicolumn{2}{c|}{$+5 \%$} \\
\hline & {$[\mathrm{M} €]$} & $\%$ & {$[\mathrm{M} €]$} & {$[\mathrm{M} €]$} & $\%$ \\
\hline Current speed & 2.3 & 51 & & 7.4 & 54 \\
\hline Load factor & 3.5 & 26.6 & & 6.1 & 26.7 \\
\hline Tariff & 3.52 & 26 & \multirow{4}{*}{4.79} & 6.05 & 26.5 \\
\hline Life time (5y) & 3.43 & 28.3 & & 5.63 & 17.5 \\
\hline Discount rate & 6.57 & 37.4 & & 3.2 & 33 \\
\hline Investment & 5.6 & 17.8 & & 3.9 & 17.8 \\
\hline
\end{tabular}

Speed of ocean currents is the major influence of energy production for the case2, increasing the speed by $5 \%$, the hours of use increase, the load factor increases and the NPV increases by 54\%. The second most sensitive variable to the NPV is the discount rate in case2. In case1, investment value is the most critical variable followed by current speed.

Case1 is a non viable possibility for this technology. Other technologies like wind power and photovoltaic, had already passed thought these "need to push" to achieve mass market they won nowadays.

To be economically viable, the price of energy sold to the grid should be at least $€ 197.8$ / MWh and this could only be possible with Government incentives such as feed-in tariffs. In case 2 the implementation of a park shouldn't be done unless the current speed is higher than $1.6 \mathrm{~m} / \mathrm{s}$.

\section{Conclusion}

The world requires clean energy sources, i.e., renewable sources without large carbon emissions. The oceans provide a major opportunity to the production of renewable energy. There is a huge potential in generating electric energy from technologies of extraction of energy from sea currents. The energy of these currents has great potential in the future of energy sources in many world countries. This energy source has several attractive features as its predictability. This work allows the conclusion that there is a great room for the development in the area of energy from sea currents. To diminish costs and guarantee the economical viability of this energy it is of great importance the development of related technologies and studies about this matter. It is possible to conclude that it is vital to have data on sea currents so that case studies can be properly analyzed. It is also shown that height and velocity of sea currents have great influence in the energy production. In the case1, the NPV is highly negative, then the project is not feasible, this is due to the still high cost of the technology. In this first phase it is necessary to give incentives for the deployment of this technology that could be, like other renewable energies, the feed-in tariffs and in this case, the feed-in tariff should exceed $€ 200 / \mathrm{MWh}$.

If this technology matures as wind power did and becomes competitive to sell on the spot electricity market then, the predictability of this source of power, is clearly an advantage when compared with other renewable like wind or waves.

\section{Acknowledgement}

A thank the Center for technical data of the Hydrographic Institute and a special recognition Nuno Pereira da Costa for having provided data from the heights of the currents of Sines.

\section{Bibliography}

[1] APREN, “Associação das energias renováveis," [Online]. Available:

http://www.apren.pt/dadostecnicos/index.php?id=549 \&cat=266. [Acedido em 2014 Abril 7].

[2] F. O. Rourke, F. Boyle e A. Reynolds, "Tydal energy update 2009," Elsevier, vol. 87, n. ${ }^{\circ}$ Applied Energy, pp. 398-409, 2010.

[3] SI OCEAN, strategic iniciative for ocean energy, "Ocean Energy: State of the Art," Europa.

[4] AQUARET: Aquatic renewable energy tecnologies, AquaRET E-learning Tool, AQUARET, 2006.

[5] EMEC, "Assessment of Tydal Energy Resource," London, 2009.

[6] J. S. Jian, "Prediction and Analysis of Tides and Tidal Currents," International Hydrographic Review, vol. IV, pp. 24-29, Agosto 2003.

[7] G. Hagerman and B. Polagye, "Methodology for Estimating Tidal Current Energy Resources and Power Production by Tidal In-Stream Energy Conversion (TISEC) Devices," EPRI, North American, 2006.

[8] A.S. Bahaj and L. E. Myers, "Fundamentals applicable to the utilization of marine current turbines 
for energy production, "Elsevier, vol. 28, Renewable Energy, pp 2205-2211, 2003.

[9] P. L. Fraenkel, "Power from marine currents," p. 14, 10 Abril 2001

[10] NOAA (National Oceanic and Atmospheric Administration, available at http://www.noaa.gov/ 